\title{
Comparisons Between International Student Recruitment Strategies in American Universities and Chinese Universities
}

\author{
Yile $\mathrm{Shi}^{1 *}$ \\ ${ }^{1}$ School of Education, University of Florida, Gainesville, Florida, 32612, US \\ *Corresponding author. Email: yileshi@ufl.edu
}

\begin{abstract}
Different countries have diversified strategies for recruiting international students due to different national conditions and traditions related to their educational achievements and outputs to a certain extent. This research aims to explore the strategies of Chinese and American universities in recruiting international students and compare the differences between these strategies of universities in the two countries. To be specific, this research will be analyzed and compared from three aspects, namely standardized grades, extra-curricular activities, and interviews in the application process. This study concludes that Chinese and American universities have great differences in recruitment strategies for international students through literature reference and analysis of examples. American universities pay more attention to standardized scores and set up standardized tests for international students as admission criteria. Chinese universities are paying more attention to the interview process in recruiting international students. Both Chinese and American universities are focusing on extracurricular activities in their recruitment strategies for international students. In contrast, Chinese universities should raise standards for international students when recruiting them. This research has implications for Chinese universities in their strategies for recruiting international students.
\end{abstract}

Keywords: International students, Recruitment strategy, Admission, China, US, Education, Standardized test, Extra-curricular activity, Interview in the admission process.

\section{INTRODUCTION}

With the acceleration of globalization, countries in the world are more closely connected. The exchanges are more frequent, which also promotes the recruitment of international students by universities to enhance international exchanges and school diversity. Under such circumstances, it is of special significance to discuss the strategies of universities in different countries in recruiting international students because it is helpful to study which strategies for recruiting international students are more effective. Universities in both China and the US pay special attention to the recruitment of international students. However, due to the differences in national conditions, traditional culture, and population, universities in the two countries have different strategies in recruiting international students, which further affects the different education results of universities in the two countries. Comparing the strategies of Chinese and American universities in recruiting international students can help universities reflect and improve. This paper will specifically present and analyze the strategies of American and Chinese universities to recruit international students and compare the differences between these strategies. It will analyze the differences between the three aspects of standardized scores, extracurricular materials, and interviews during the application, aiming to inspire Chinese universities to improve their recruitment strategies for international students.

\section{INTERNATIONAL STUDENT RECRUITMENT STRATEGIES IN AMERICAN UNIVERSITIES}

American universities are among the top in the world in terms of academic ability, giving top American universities the power to set stricter admissions criteria. According to the 2021 Best Global Universities Rankings of U.S. News, 8 out of 10 of the top 10 universities in the world are from the US [1]. When recruiting international students, American universities 
pay attention to standardized scores, divided into language proficiency tests and academic proficiency tests. First of all, American universities attach great importance to international students' language proficiency test scores since they can measure English language proficiency in both daily life and academic area. For international students whose mother tongue is not English, if they want to study in the United States, they need to reach the corresponding level in English to guarantee the quality of their study in the university. The TOEFL test is one of the most common language tests in the United States. Most American universities require TOEFL scores from international students who attended high school outside the United States. For example, according to Stanford's website, the university will require applicants whose first language is not English or whose primary school language is not English to provide scores from English proficiency tests, including TOEFL, IELTS, and the Duolingo Test of English [2].

As the country with the leading education system in the world, the United States is known for its standardized tests, such as the SAT, GRE, etc. Unlike TOEFL, tests like the SAT are designed to measure a student's academic ability rather than focusing on mastery of English. For example, as one of the entrance exams for American universities, SAT tests students' analytical ability and comprehension ability of literature. Hence, it evaluates students' overall ability to score [3]. These tests have become the threshold that international students must overcome to get into American universities and have made a significant contribution to the recruitment of high-quality international students to the United States. In a word, American universities require international students to have a high level of English to ensure their basic English skills and require international students to provide SAT scores to prove their academic ability. In addition to the TOEFL and SAT tests mentioned, American universities also require international students to submit transcripts from their high schools when admitting them. This highlights the importance that American universities place on the student's learning experience and process, rather than just focusing on a test result. This highlights the strict requirements and considerations that American universities have when admitting international students.

However, tests and grades are not the only measure of international students' overall quality of admission into an American university. Admission criteria at most American universities focus not only on academic ability but also on areas other than academics, which constrain applicants' acceptance rates. In addition to standardized grades, international students are also required to provide information about their extracurricular activities, internships, interests, and personal statements relevant to their abilities and characteristics. In the recruitment process, the recruitment assessment method adopted by American universities includes self-statement, extracurricular experience, scientific research activities, volunteer experience, teacher recommendation, etc. [4]. Cornell University, for example, requires international students to submit recommendations from counsellors, faculty evaluations, and midyear reports along with standardized test scores to assess student performance in addition to academic performance [5]. Many American universities place special emphasis on students interested in the world or have special interests or achievements in a particular field. This also gives rise to the comprehensiveness and diversity that they emphasize in their admissions [6]. Therefore, American universities pay more attention to students' multi-faceted performance and comprehensive quality in international enrollment and pay much attention to students' characteristics besides academic performance.

\section{INTERNATIONAL STUDENT RECRUITMENT STRATEGIES IN CHINESE UNIVERSITIES}

Chinese universities have different strategies for international student enrollment based on teaching level and ranking. Some Chinese universities have established an independent evaluation system for the quality of foreign students as an evaluation criterion to select international students. For example, some of China's topranked universities, including Tsinghua University and Fudan University, adopt the entrance test for foreign students. This form of the independent setting of examination and assessment criteria, known as independent admission tests, focuses on the admission of international students according to the requirements and preferences of different universities [7]. This selection method is conducive to ensuring the comprehensive quality and academic level of international students. Still, it is only used in the context of Chinese universities with high ranking and teaching standards.

However, the above independent admissions mode only exists in China's top universities and is not universal. By contrast, the test-free approach is the most popular among Chinese universities' strategies for recruiting international students. This means that many Chinese universities ignore standardized test scores when recruiting international students, instead simply conducting interviews and reviewing materials. Except for a few top universities, international students can easily get into Chinese universities that local students find hard to get into just by using Chinese language proficiency tests and high school grades. Many universities have even lower requirements for Chinese proficiency tests, giving more opportunities to international students. Tsinghua University, for example, has also lowered the requirement for foreign students for the Chinese language proficiency test for every international student from level six to level five [8]. This policy is the same as some Chinese universities hope to 
increase the proportion of international students in the overall university by lowering the requirement of international students to improve the international reputation and rankings of the university. When recruiting international students, Zhejiang University values high school grades and Chinese proficiency tests of foreign students most, rather than standardized tests that measure students' academic proficiency. However, the application materials are required to include a personal statement, recommendation letter, and other materials, which is not enough to guarantee students' ability in the academic field [9].

While such admissions have increased the proportion of international students at some Chinese universities, they have led to a number of negative effects. As some foreign students find it easy to enter Chinese universities, they are very likely to be unmotivated and even neglect their studies. However, some Chinese universities have slightly higher admission policies, such as Fudan University, which requires international students whose first language is not English to submit a TOEFL score of 90 or an IELTS score of 6.5 in its economics undergraduate program [10].

\section{COMPARISONS BETWEEN INTERNATIONAL STUDENT RECRUITMENT STRATEGIES IN AMERICAN UNIVERSITIES AND CHINESE UNIVERSITIES}

\subsection{Requirements for Standardized Grades}

In contrast, American universities attach more importance to and require international students to standardized scores. For American universities, standardized scores can be seen as a threshold for international students to apply to universities, but Chinese universities have lowered the bar. There are national, standardized score tests in the United States that international students can take and submit when applying to universities [11]. For Chinese universities, there is no specific academic proficiency test for international students regulated by the government, and scores on the Chinese proficiency tests are not required in most Chinese universities [12].

\subsection{Requirements for Extra-Curricular Materials}

Both American and Chinese universities require extracurricular materials when recruiting international students. The items included in the extracurricular materials are similar, such as personal statement, research experience, internship experience, etc. The only difference is that since American universities have higher requirements for standardized scores, extracurricular materials are used as supplementary material. Due to the lack of standardized tests in the admission process for international students, Chinese universities have included extra-curricular materials in the most important review.

\subsection{Requirements for the Interview in the Application Process}

Most Chinese universities have mandatory interview requirements, while American universities rarely have mandatory interview requirements. This is because there are relatively few international students applying to Chinese universities. For Chinese universities, the interview process is a test of international students' Chinese proficiency and a more in-depth assessment of the candidate's strengths and weaknesses [13]. Hence, university admissions officers have the time and energy to interview and screen applicants. However, the number of international students applying to American universities is very high. As a result, admissions officers at American colleges do not have the time to interview numerous international applicants one by one. Instead, they are selected based on written materials. The interview approach has brought advantages and disadvantages to universities in selecting international students. Due to the small number of applicants, Chinese universities have time to fully understand each student and learn about students' communication skills and personality characteristics through conversation, which helps the application officers consider objectively, rather than just based on grades. However, there may be risks in this process. For example, college interviewers may select students according to their own preferences and biases during the interview. Some international students are more extroverted. Then they may be more outgoing in the interview, which makes them more attractive to the interviewers. However, it is at a disadvantage for those students who are introverted and have the excellent academic ability but do not know how to show themselves, which may lead to unfair results.

\subsection{Reasons for the Differences in International Student Recruitment Strategies}

From the above analysis, it can be seen that Chinese universities and American universities have some similarities and differences in their admission strategies for international students, and exploring the reasons for those differences is of great significance to give Chinese universities room for improvement. As Bingqi Xiong, vice-president of the 21st Century Education Research Institute, Beijing, found out, the proportion of international students is an important indicator of a university's global influence [8]. He illustrated this by comparing the proportion of international students at Tsinghua University with that at Harvard University. Only 5.8 percent of the student body is foreign, far lower than the 20 percent at universities like Oxford and 
Harvard [8]. This difference in numbers prevents Tsinghua from choosing foreign students the way Harvard does with Chinese students. As mentioned earlier, some Chinese universities have deliberately lowered the admission requirements for international students to expand the proportion of international students and improve the university's international ranking. However, this intention has led to injustice in the recruitment process. As a country with complex race composition and immigrants from different countries, the United States has different ethnic groups within the country, which greatly contrasts with the situation in China. As a result, American universities have a distinct advantage in recruiting students of different races and nationalities and do not need to lower their admission standards to attract international students.

\section{CONCLUSION}

To sum up, this paper specifically discusses the differences between the strategies of American and Chinese universities in recruiting international students and analyses the reasons for these differences. It can be seen from the analysis that American universities pay attention to standardized scores and extracurricular activities when recruiting international students and have relatively uniform and standard enrollment requirements. In contrast, Chinese university es have lower requirements when recruiting international students, and their recruitment methods vary greatly from university to university. By comparing the differences among these strategies, we can conclude that Chinese universities should set stricter requirements for international students to improve the standard of international students admitted.

\section{REFERENCES}

[1] The Best Universities in the World. (2021). Usnews.com.

https://www.usnews.com/education/best-globaluniversities/rankings

[2] Stanford University. (2019). Undergraduate Admission: Stanford University. Stanford.edu. https://admission.stanford.edu/

[3] Poulsen, J., \& Hewson, K. (2013). Standardized testing: Fair or not? Uleth.ca. https://www.uleth.ca/teachingcentre/standardizedtesting-fair-or-not

[4] Huang, I. Y., Raimo, V., \& Humfrey, C. (2014). Power and control: Managing agents for international student recruitment in higher education. Studies in Higher Education, 41(8), 1333-1354.

https://doi.org/10.1080/03075079.2014.968543
[5] Cornell University. (2019). Admissions | Cornell University. Cornell.edu. https://www.cornell.edu/admissions/

[6] Onk, V. B., \& Joseph, M. (2017). International student recruitment techniques: A preliminary analysis. Journal of Academic Administration in Higher Education, 13(1), 25-34. https://eric.ed.gov/?id=EJ1139145

[7] Gao, Y., \& Liu, J. (2020). International student recruitment campaign: Experiences of selected flagship universities in China. Higher Education. https://doi.org/10.1007/s10734-020-00503-8

[8] Sharma, Y. (2017). Row over "easy" admission for international students. University World News. https://www.universityworldnews.com/post.php?st ory $=20170222122830767$

[9] Ma, J., \& Zhao, K. (2018). International student education in China: Characteristics, challenges, and future trends. Higher Education, 76(4), 735-751. https://doi.org/10.1007/s10734-018-0235-4

[10]Fudan University. (2021). 2021 Undergraduate International Program in Economics. Iso.fudan.edu.cn. https://iso.fudan.edu.cn/isoenglish/16217/list.htm

[11] EducationUSA. (2015, December 10). Prepare For U.S. Standardized Tests, Undergraduate. Education USA. https://educationusa.state.gov/your-5-stepsus-study/research-your-

options/undergraduate/prepare-us-standardizedtests

[12] Floris, S. (2020, May 12). How to Apply for Admission into Chinese Universities. China Scholar. https://www.china-scholar.com/howapply-admission-to-chinese-universities/

[13] Chen, X. (2017). A change in admission requirements for internationals applying to chinese universities is causing a debate over education fairness between local and foreign students - global times. Www.globaltimes.cn 